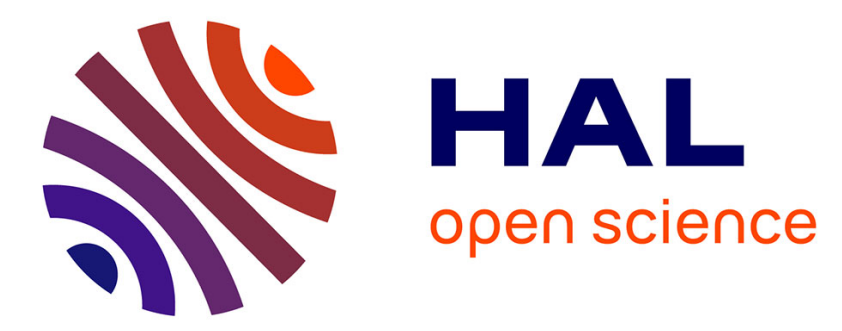

\title{
First assessment of effects of global change on threatened spiders: Potential impacts on Dolomedes plantarius (Clerck) and its conservation plans
}

Boris Leroy, Mauro Paschetta, Alain Canard, Michel Bakkenes, Marco Isaia, Frédéric Ysnel

\section{To cite this version:}

Boris Leroy, Mauro Paschetta, Alain Canard, Michel Bakkenes, Marco Isaia, et al.. First assessment of effects of global change on threatened spiders: Potential impacts on Dolomedes plantarius (Clerck) and its conservation plans. Biological Conservation, 2013, 161, pp.155 - 163. 10.1016/j.biocon.2013.03.022 . hal-03334391

\author{
HAL Id: hal-03334391 \\ https://hal.science/hal-03334391
}

Submitted on 3 Sep 2021

HAL is a multi-disciplinary open access archive for the deposit and dissemination of scientific research documents, whether they are published or not. The documents may come from teaching and research institutions in France or abroad, or from public or private research centers.
L'archive ouverte pluridisciplinaire HAL, est destinée au dépôt et à la diffusion de documents scientifiques de niveau recherche, publiés ou non, émanant des établissements d'enseignement et de recherche français ou étrangers, des laboratoires publics ou privés. 


\section{First assessment of effects of global change on threatened}

\section{2 spiders: potential impacts on Dolomedes plantarius (Clerck)}

3 and its conservation plans

$4 \quad$ Running title: Effects of global change on a vulnerable spider

5

6 Boris Leroy ${ }^{\mathrm{a}}$, Mauro Paschetta ${ }^{\mathrm{b}}$, Alain Canarda, Michel Bakkenes ${ }^{\mathrm{c}}$, Marco Isaiab \&

$7 \quad$ Frédéric Ysnel $^{\mathrm{a}}$

8 aEquipe Biodiversité et Gestion des Territoires et Service du Patrimoine Naturel, MNHN,

9 Université de Rennes I, 263 Av. du Gal. Leclerc 35042 Rennes Cedex, France

10 bDepartment of Life Sciences and Systems Biology, Via Accademia Albertina, 13 -

11 Torino, Italy

12 cNetherlands Environmental Assessment Agency (PBL), PO Box 303, 3720 AH Bilthoven,

13 The Netherlands

14

Corresponding author: Boris Leroy

Mail: leroy.boris@gmail.com

Tel.:+33.666.021.327

Postal address: Equipe Biodiversité et Gestion des Territoires, Université de Rennes I, 263 Av. du Gal. Leclerc 35042 Rennes Cedex, France 


\section{Abstract}

Our view of the future of biodiversity remains limited to a restricted number of taxa, and some taxa, such as spiders, have been largely omitted. Here we provide the first assessment of effects of global change on threatened spiders using a red-listed vulnerable spider, Dolomedes plantarius (Clerck, 1757) as an example. We aim at applying this assessment to assist two conservation actions for this species, including a translocation program. We compiled all the available data on D. plantarius and modelled its current and future distributions on the basis of both climate and land cover variables at a fine resolution (o.1 degrees). We applied an ensemble modelling procedure on the basis of eight modelling techniques, and forecasted the future distribution ranges for two emission scenarios (A1 and B2) and three general circulation models. Despite uncertainty regarding the predictions, the models performed very well, and consensus emerged for models and climate scenarios to predict significant negative effects on the current distribution range of this species. In the U.K., the translocated population and one out of three natural populations were predicted to remain in highly suitable environmental areas. In France, one out of six locations was predicted to remain suitable in the future. Given the phylogeographic background of this species, the predicted effects of environmental changes should be considered seriously, especially for the long-term viability of conservation programs. Our study demonstrated the importance and feasibility of studying the effects of climate change by the means of species distribution models on taxa with limited available data, such as spiders.

Key-words: Conservation biogeography, species distribution models, translocation, reintroduction, reinforcement, vulnerable species. 
47 Due to man-induced changes (climate change, habitat loss, biological invasions) the Earth 48 is undergoing a state shift (Barnosky et al., 2012), so methods to forecast biological changes are being increasingly developed for biodiversity conservation (Dawson et al., 2011). Empirical niche models have been developed as a tool to predict the effects of both climate change and habitat loss on biodiversity conservation (Bellard et al., 2012), and numerous advances in methodology have been developed to improve our ability to predict the future of biodiversity (e.g. Araújo et al., 2005; Thuiller et al., 2009; Barbet-Massin et al., 2010). Nevertheless, our view of the future of biodiversity remains considerably limited by several issues, resulting in challenges to overcome (Bellard et al., 2012). Particularly, the pervasive taxonomic bias in studies predicting the future of biodiversity is strongly reminiscent of the pervasive bias in conservation research identified in 2002 (Clark and May, 2002). Indeed, although invertebrates represent more than 15 times the biodiversity of all mammals, birds, reptiles, amphibians and plants together (Chapman, 2009), most studies have focused on the latter groups (Bellard et al., 2012). However, it has been shown that range shifts due to climate change within the past 40 years in Great Britain, were stronger in many invertebrate taxa than in both birds and mammals (Hickling et al., 2006). For example, spiders have shifted the northern margin of their range on average $84 \mathrm{~km}$ northwards, whereas birds and mammals have shifted on average 29 and $22 \mathrm{~km}$ northwards respectively. Nevertheless, to date, only one study forecasting the effect of climate change on spider taxa has been published, and this study focused on a spider with a restricted range (Jiménez-Valverde and Lobo, 2007a). This lack of studies on spiders is surprising, since spiders are known to be excellent indicators because of their strict ecological and biotope requirements (Marc et al., 1999; Prieto-Benítez and Méndez, 2011). Therefore, to improve our predictions of forecasted biodiversity, new studies are 
The study by Jiménez-Valverde \& Lobo (2007a) focused on the endangered species Macrothele calpeiana, a spider endemic to the Iberian Peninsula; it was predicted that climate change will negatively affect this species, with a reduction and fragmentation of its potential habitat. Further studies of the potential effects of climate change on spiders are therefore required to grasp the trend of climate change impacts on spiders. Particularly, new studies on threatened spiders are needed to predict whether global changes are likely to benefit or further threaten them. Only 30 spider species have red-list statuses (IUCN, 2012a), and international, fine-scale distribution data is absent for most spiders. Only six European spider species are included in the IUCN red-list, and of these, five are restricted endemics. However, the western Palearctic fen raft spider Dolomedes plantarius (Clerck, 1757) is a widespread species listed as Vulnerable (IUCN, 2012a). Furthermore, this species is subject to a conservation plan in the United Kingdom (Smith, 2000) where a translocation program was initiated in 2010 (Smith \& Baillie, 2011). So, this emblematic and widespread species is the best candidate for a first large-scale study of the potential effects of climate change on threatened spiders. Besides, in France, this species was selected for the Strategy for Creation of terrestrial Protected Areas (SCAP), which aims to preserve a total $2 \%$ of the French metropolitan territory by 2020 , on the basis of selected species from diverse taxa. However, D. plantarius will be included in the SCAP only if knowledge about its current distribution and climatic threat is improved (Coste et al., 2010). Our first objective is to forecast and quantify the potential effects of climate change on D. plantarius, and the resulting impacts on the United Kingdom and French conservation programs.

In order to be accurate and relevant, forecasts of future biodiversity must be based on solid prediction models, making highly accurate predictions about the relationship between species and environmental variables. So far, published examples of species distribution models on spiders have been based on a limited set of models (JiménezValverde and Lobo, 2007a; Jiménez-Valverde et al., 2011; Stockman et al., 2006) and have not included recent improvements of species distribution models, such as ensemble 
forecasts (Araújo \& New, 2007; Thuiller et al., 2009). Furthermore, to reduce uncertainty, future projections should be based on different climate change scenarios as well as different general circulation models (Buisson et al., 2010), which was not the case for the study by Jiménez-Valverde \& Lobo (2007a). Therefore, as a second objective we aimed to apply a rigorous modelling framework with a large set of models to assess the suitability of species distribution models for a spider species distributed throughout a large spatial area, such as $D$. plantarius.

We therefore modelled the current and future distributions of $D$. plantarius on the basis of environmental variables for two climate scenarios (A1 \& B2). We used both climatic and land cover variables since $D$. plantarius, as an ectotherm, is strongly dependent on temperature and humidity; it is a semi-aquatic spider with a strong sensitivity to habitat change and disturbance (Duffey, 1995, 2012; Smith, 2000). Since spiders are strongly dependent on local conditions and habitat (Marc et al., 1999), we used variables at the finest available resolution (o.1 degree). First, we analyzed the accuracy of models and ensemble forecasts according to different evaluation metrics. We then quantified the potential effects of climate change on the distribution range of $D$. plantarius. We analyzed the impacts of climate change on the current French and United Kingdom conservation programs for this species. We finally analyzed the degree of uncertainty underlying our predictions.

\section{Methods}

\subsection{Climate data}

We used bioclimatic data from the WorldClim database (Hijmans et al., 2005) for model training and projection of the current potential distribution of $D$. plantarius. As no prior knowledge exists about the relationship between $D$. plantarius and climate variables, we selected bioclimatic variables that were not intercorrelated (Pearson's $\mathrm{r}<0.70$ ) and predicted the current distribution of $D$. plantarius best, according to different models (see 
Appendix A in Supplementary material). The chosen variables were annual temperature range, maximum temperature of the warmest month, minimum temperature of the coldest month, mean temperature of the wettest quarter, mean diurnal range and annual precipitation (averaged for the period 1950-2000). All bioclimatic variables were resampled at 0.1 degree resolution by bilinear interpolation to match the resolution of land cover variables (see below).

Two IPCC emission scenarios were used for the projection of future climate: A1B (maximum energy requirements, emissions balanced across fossil and non-fossil sources) and B2A (lower energy requirements and thus lower emissions than A1B) (IPCC, 2007). We chose three future periods: 2020s, 2050s and 2080s (averaged from 2010 to 2039 , 2040 to 2069 and 2070 to 2099 respectively). Because uncertainty in forecasting future distributions is largely related to global circulation models (Buisson et al., 2010), we used three different global circulation models that simulated the impact of A1B and B2A scenarios on future climates. We chose the models that were available for both our climate scenarios: Hadley Centre Coupled Model version 3 (HADCM3), Coupled Global Climate Model (CGCM, A1B: version 3.1 (t47), B2A: version 2) and the Commonwealth Scientific and Industrial Research Organisation model (CSIRO, A1B: Mk3.o, B2A: Mk2). These models were downscaled statistically using the Delta method (Ramirez-Villegas and Jarvis, 2010). The models were downloaded from the Global Climate Model data portal (http://www.ccafs-climate.org/spatial_downscaling).

\subsection{Land cover data}

We used land cover variables from the GLOBIO3 land model (Alkemade et al., 2009) for model training and projection of the current potential distribution of $D$. plantarius. Current land cover variables were obtained from the GLOBIO3 output for 2000. We also included water body data (sum of lakes, reservoirs and rivers) from the Global Lakes and Wetlands Database (Lehner and Döll, 2004) because of the semi-aquatic nature of $D$. plantarius. We selected three variables that significantly explained the distribution of $D$. 
plantarius according to the same protocol as climatic variables (see Appendix A): water bodies, artificial areas and cultivated and managed areas.

155

156

Regarding the future projections of artificial areas and cultivated and managed areas, we used two scenarios of the latest Rio+20 pathways based on the GLOBIO3 land model (PBL Netherlands Environmental Assessment Agency, 2012). The Trend scenario followed the current trend in emissions and was therefore similar to the A1B scenario. Conversely, the Decentralised solutions scenario was similar to the B2A scenario. Therefore, we associated climate data to land cover data according to the similarity between scenarios: A1B with Trend, and B2A with Decentralised solutions. Land cover data were projected for 2020 and 2050, but not for 2080, because beyond 2050 the uncertainty became too large. Nevertheless, since the current distribution of $D$. plantarius was predicted by both climate and land cover, we assumed that both should be used to predict the future distribution, even if the projection of one driver stopped before the other. Hence, we projected the distribution of $D$. plantarius in 2080 by combining the 2080 climate variables and the 2050 land cover variables. We assumed that, in spite of this introduced bias, the projected distribution would be closer to its actual range than a projection solely on the basis of climate variables, and besides, water bodies were not predicted to change until 2080.

\subsection{Species data}

We made an extensive search for records of $D$. plantarius presence in the published and grey literature, on internet databases and with arachnologists (see Appendix B and C). We discarded uncertain records as well as records before 1950. However, although our bioclimatic variables were averaged for 1950-2000, we kept records for the period 20002010 because many new localities were recorded, especially in previously poorly sampled areas such as eastern European countries and Scandinavia. Hence, we gathered data on the global distribution of $D$. plantarius, to avoid misleading conclusions due to the use of data from a restricted range of occurrence (Barbet-Massin et al., 2010). To limit the sampling bias towards better sampled areas in western and central Europe, we aggregated 
records into 0.1 degree cells corresponding to the resolution of our environmental variables. We specifically studied the future effects of climate change on the United Kingdom and French locations, where populations of $D$. plantarius had been recorded (locations in Fig. D.1) relative to their respective conservation plans. Three locations with large natural U.K. populations were studied: "South Wales", "Pevensey levels" and "Redgrave and Lopham Fen”. Similarly, the translocation areas chosen in the U.K. conservation program were studied. In France, six locations where D. plantarius had been recorded recently (i.e., after 2000) were studied (see Fig. D.1).

\subsection{Modelling process}

We projected the current and future distributions of $D$. plantarius under the BIOMOD platform (Thuiller et al., 2009) version 2.0, which now includes the modelling technique MaxEnt. We used 8 niche-based modelling techniques: (1) generalized linear model (GLM, McCullagh \& Nelder, 1989); (2) generalized additive model (GAM,Hastie and Tibshirani, 1990); (3) generalized boosted models (GBM, Ridgeway, 1999); (4) classification tree analysis (CTA, Breiman et al., 1984); (5) flexible discriminant analysis (FDA, Hastie et al., 1994); (6) multivariate adaptive regression splines (MARS, Friedman, 1991); (7) random forests (RF, Breiman, 2001); (8) maximum entropy (MaxEnt, Phillips et al., 2006).

As the chosen models required data on both species presence and the available environmental conditions, we generated 5 sets of 1000 randomly selected pseudoabsences with equal weighting for presence and absence (Barbet-Massin et al., 2012). We calibrated the models with $70 \%$ of the data selected at random and then evaluated the predictive performance of each model on the remaining 30\% (Guisan \& Thuiller, 2005) with two evaluation metrics: the area under the relative operating characteristic curve (AUC, Fielding \& Bell, 1997) and the true skill statistic (TSS, Allouche et al., 2006). This process was repeated five times in order to obtain an average value of model performances, and the final models were calibrated on $100 \%$ of the data. For each model, 
we evaluated the response of the species to environmental predictor variables with the evaluation strip method (Elith et al., 2005).

In order to produce robust forecasts of the distribution of $D$. plantarius, we applied an ensemble forecast method to combine the 8 modelling techniques (Araújo \& New, 2007; Thuiller et al., 2009). Models with TSS evaluations below 0.6 were discarded, and the current and future consensus distributions were obtained by averaging distributions with weights proportional to their TSS evaluation. Final maps were then obtained by averaging ensemble forecasts from the 10 pseudo-absence runs. This resulted in one current probability distribution map and 3 future probability distribution maps per year and per scenario (because we used 3 GCMs). Future probability maps were therefore averaged per year and per scenario. Probability maps were transformed into maps of suitable vs. non suitable areas by choosing the probability threshold that maximized the TSS value. This should ensure the most accurate predictions since it is based on both sensitivity and specificity (Jiménez-Valverde and Lobo, 2007b; Liu et al., 2005). We obtained one current binary distribution map and 3 future binary distribution maps per year and per scenario. Consensus binary maps were obtained attributing presence when the majority of GCMs (i.e., 2 out of 3) predicted presence, otherwise we attributed absence.

Since the projected maps were at a 0.1 degree resolution, not all pixels were of equal area. Hence, pixel values were weighted according to the pixel area to calculate variations in climate suitability. To account for uncertainty in predictions, the environmental suitability of French and English populations was divided into three categories depending on the suitability cut-offs (see Table 1): "Unsuitable”, “Low suitability” and "Suitable”.

\section{Results}

All the calibrated models performed very well with an average TSS value of 0.87 and an average ROC value of 0.98 (see Figure E.1). Intriguingly, all the calibrated RF models had 
TSS and ROC values of 1, possibly suggesting over fitting, but as the maps produced by RF were consistent and similar to the other models, we did not discard them for the ensemble forecast. Hence, almost all the calibrated models were included in the ensemble forecast, except for some of the CTA models.

The fitted response curves of $D$. plantarius showed a strong response of the species to the selected environmental predictor variables (see Figure F.1). Firstly, D. plantarius showed a stenoecious response to three temperature variables: temperature annual range (highest probability at $29.5^{\circ} \mathrm{C}$ ); maximum temperature of warmest month (highest probability at $21.5^{\circ} \mathrm{C}$ ) and minimum temperature of coldest month (highest probability at $\mathrm{O}^{\circ} \mathrm{C}$ ). Three variables appeared as limiting for this species: average temperature of the wettest quarter (strong decrease in probability below $7.5^{\circ} \mathrm{C}$ and above $20^{\circ} \mathrm{C}$ ); mean diurnal temperature range (decrease in probability above $9^{\circ} \mathrm{C}$ ) and water bodies (decrease in probability above $55 \%$ of the land occupied). Three variables showed a slight negative effect: annual precipitation (decrease above $750 \mathrm{~mm}$ ); cultivated and managed areas (decrease above 62.5\% of land occupied) and artificial surfaces (very slight negative relationship).

\subsection{Current potential range of $\mathrm{D}$. plantarius}

The current core range of D. plantarius is located in northern central Europe with numerous areas of high environmental suitability isolated from the core, e.g. in northern Spain, western France and Eastern Europe (Fig. 1A).

The average threshold for conversion of environmental suitability maps into maps of suitable and unsuitable areas was relatively low, at 0.171, with values ranging from 0.133 to 0.352 according to the pseudo-absence run. The projected distribution of suitable areas for D. plantarius is composed of a large core area with continuity between large suitable areas. Numerous small patches of suitable areas occur in south-eastern to eastern Europe. 
There will be a strong global decrease in environmental suitability for areas south of the current distribution range of $D$. plantarius, with stronger tendencies for scenario $\mathrm{A} 1 \mathrm{~B}$ (Fig. 1B., D., F.) than for scenario B2A (Fig. 1C., E., G.). On the other hand, there will be a global increase in environmental suitability for areas north of this spider's current range. Areas with previously very low suitability will increasingly become suitable throughout northern Europe, with more areas having a higher suitability for scenario A1B (Fig. 1B., D., F.) than for scenario B2A (Fig. 1C., E., G.). Suitability at the current core of the range will progressively decrease (Fig. $1 \mathrm{~A}-\mathrm{E}$ ) to reach a minimum by 2080 regardless of the scenario (Fig. 1 F-G). This will lead to a progressive north-eastward shift of the core, from northern Germany to southern Sweden. Practically all of the current areas of high environmental suitability will have a lower suitability in the future, regardless of the scenario.

The most striking result regarding the distribution of suitable areas is the dramatic disappearance of areas currently suitable in the southern part of the current range of $D$. plantarius for both scenarios (Fig. 2A-G). This process will first result in fragmentation and isolation of the southern parts of the range by 2020 (Fig. $2 \mathrm{~A}-\mathrm{C}$ ), and then in a reduction in size of the isolated patches of suitable areas by 2050 (Fig. 2D-E), to very small remnants of their original size by 2080 (Fig. $2 \mathrm{~F}-\mathrm{G}$ ). Conversely, newly suitable areas will appear progressively to the north of its current range in areas previously unoccupied by D. plantarius, with even more areas appearing under scenario A1B (Fig. 2B., D., F.) than scenario B2A (Fig. 2C., E., G.).

By 2080, we can expect a net decrease of $33.5 \%$ (B2A) to $42.1 \%$ (A1B) of areas that are currently suitable for D. plantarius (Fig. 3). On the other hand, we can expect the appearance of suitable areas in proportions equal to $45.4 \%(\mathrm{~B} 2 \mathrm{~A})$ to $65.9 \%$ (A1B) of the current range of $D$. plantarius (Fig. 3). The appearance of these newly suitable areas will mostly occur to the north of the current range; however new areas will appear south of the 
current range, at high altitudes in the Alps. Overall, the predicted net change in suitable range of $D$. plantarius will range from an increase of $11.9 \%$ (B2A) to $23.9 \%$ (A1B).

Within suitable areas, the average environmental suitability is predicted to decrease progressively, in spite of a slight increase in suitability for the whole prediction area (Table 1A.). Furthermore, the environmental suitability of areas with known populations of $D$. plantarius will decrease by an order of magnitude three (B2A) to six (A1B) times higher than within the full range of suitable areas. As a result, by $2080,15.2 \%$ (B2A) to $17.5 \%$ (A1B) of areas with known populations will become unsuitable (see Fig. G.1); most of these populations are in the southern part of the range.

\subsubsection{Impacts on the UK translocation program}

There will be a net decrease of environmental suitability for the three natural English populations, and by 2080 the environmental conditions are likely to significantly decrease the suitability of two out of three naturally occurring populations according to scenario A1B (Table 1B). Conversely, according to scenario B2A, only the location of "Redgrave and Lopham Fen" will significantly decrease in suitability (Table 1B). Interestingly, two populations will be less impacted, with smaller decreases in environmental suitability: the natural population occurring in "South Wales", and the translocated population. For both scenarios, their locations will remain suitable, with a high suitability (Table 1B). These predicted changes are to be related to the strong predicted changes in temperature variables in these sites (see Fig. F.2-9).

\subsubsection{Impacts on the French conservation program}

There will be an important decrease of environmental suitability for French populations of D. plantarius, with three out of six populations likely to be in unsuitable environmental conditions by 2080 for both scenarios (Table $1 \mathrm{C}$ ). Among the three suitable populations, two will decrease significantly in environmental suitability, with a low suitability for both scenarios. On the other hand, the population of "Lac d'Hourtin" is more likely to remain in 
suitable environmental conditions, with higher suitability values predicted for both emission scenarios. These predicted changes are also linked to the strong predicted changes in temperature variables in these sites (see Fig. F.2-9).

\subsection{Uncertainty analysis}

Substantial variation in the changes of suitable areas was observed among calibrated models, pseudo-absence runs and global circulation models (see Fig. H.1). Predicted changes varied with length of time (the farther away the prediction, the higher the range of predicted values) and scenarios (slightly more variation was observed for A1B than for B2A). Hence, the greatest variation was observed for 2080 and scenario A1B. When calibrated models were pooled in ensemble forecasts, much less variation was observed, but substantial differences remained, particularly among the global circulation models (Fig. 4; see Fig. H.2 and H.3). Similarly, predicted changes varied with time and scenarios (Fig. 4). The greatest variation was observed for 2080 and scenario A1B, where the predicted decrease in suitable areas ranged from $24.5 \%$ to $71.8 \%$ and the predicted increase was $43.0 \%$ to $110.1 \%$. As a result, the predicted net change ranged from $-20.0 \%$ to $+79.9 \%$.

\section{Discussion}

\subsection{Global change effects on the vulnerable spider, Dolomedes plantarius}

From this first forecast of the effects of both climate and land cover changes on the spider taxon, we predicted the potential future distribution of $D$. plantarius, quantified future changes in environmental suitability, and analyzed the impacts of global changes for two conservation programs. The studied drivers of global changes, climate and land cover, will have significant effects on the distribution range of $D$. plantarius, with a large predicted shift towards the northeast of the range of suitable environmental conditions. Furthermore, there will be an ongoing decrease of environmental suitability within the suitable range throughout the $21^{\text {st }}$ century, and this decrease will be even greater in 
locations where populations have been found. By the end of the $21^{\text {st }}$ century, 15 to $17 \%$ of the current known populations will face environmental conditions which are predicted as unsuitable by the models and have never been met by the species before. These results are strengthened by the observed stenoecy of $D$. plantarius to several of the environmental predictor variables, especially to temperature variables. Nevertheless, global changes will also create newly suitable areas to the north, in addition to those at higher altitudes of the current suitable range of $D$. plantarius.

Hence, populations of $D$. plantarius threatened by global changes will either have to move to find suitable environmental conditions, or to adapt to their new environmental conditions. However, the ability of $D$. plantarius to disperse towards suitable areas is questionable. Populations of $D$. plantarius have been shown to be genetically distinct, even at small scales (Vugdelić, 2006), which suggests that dispersion events are either rare or rarely successful in establishing new populations. Unlike many spider species which disperse aerially (Marc et al., 1999), D. plantarius has not been reported to do this (Duffey, 2012), although other members of the family do (e.g. Greenstone et al., 1987). Long-distance terrestrial dispersion is unlikely because of the strict attachment of $D$. plantarius to water surfaces (Duffey, 2012); nevertheless, ballooning experiments should be conducted to validate this hypothesis. On the other hand, water dispersal is more plausible because the spider can stand and move actively on water surfaces (Gorb and Barth, 1994), and also move passively by sailing (Suter, 1999). This latter dispersal mode could explain the large current range of $D$. plantarius according to genetic analyses: $D$. plantarius could have spread throughout its range during interglacial stages, when melting ice provided large interconnected areas of suitable habitats (wetland areas, ponds and lakes) (Vugdelić, 2006). These large areas of suitable habitats have now been reduced to fragments with considerably less connections.

If this hypothesis was true, then our findings would have important implications for the conservation of D. plantarius. Firstly, populations that are taken out of the range of 
suitable environmental conditions in the future will either have to adapt or become extinct, because the dispersal solution is unlikely. Dispersal is even more unlikely because the stenotopic nature of $D$. plantarius makes it difficult to encounter suitable habitats. This species is extremely sensitive to several habitat characteristics such as water quality and vegetation structure (Duffey, 1995, 2012; Smith, 2000; Harms et al., 2009) and disturbances in habitat have already led to local extinctions (Bonnet, 1952; Gajdoš et al., 2000; Smith, 2000). Consequently, global changes will act as a further threat to this vulnerable species. The predicted decrease in environmental suitability may weaken existing populations and further increase their sensitivity to habitat change.

Secondly, D. plantarius will probably not be able to reach all of the large areas of suitable environmental conditions that may appear in the future, without help. Barriers of unsuitable areas will probably preclude the species from reaching future suitable sites such as Ireland and isolated fragments of north-eastern Europe. If the species is able to track changes in environmentally suitable conditions rapidly, then it might reach some areas of high suitability in the future, such as in the United Kingdom. However, if the species is not able to track changes fast enough, then it will become isolated by barriers of unsuitable areas. Besides, some populations have orographic barriers blocking their escape path toward more suitable areas, such as the isolated Italian populations which are blocked by the Alps. The only option available for these populations is adaptation to the new environmental conditions. These populations at the southern tip of the range will be among the first to be impacted, and could be monitored to corroborate or invalidate our predictions. Conversely, D. plantarius has more chance of tracking changes in Scandinavia, because suitable areas are predicted to remain interconnected in the future, and the availability of water habitats will render dispersal by water possible too. Hence, Scandinavia might eventually become the last refuge for D. plantarius, if the predicted trends persist beyond 2080 . 
The natural English populations of $D$. plantarius are predicted to be threatened in the future by important decreases in environmental suitability; depending on the emission scenario, one to two out of three natural populations are likely to experience significant decreases in environmental suitability. On the other hand, although the locations chosen for the translocation program have been chosen regardless of the future climatic conditions, our models predicted that they were located in areas of high environmental suitability which will be threatened only marginally by environmental changes compared to the other populations. Our results imply that it is vital that the translocation plan is successful for the conservation of $D$. plantarius in the United Kingdom, given the upcoming changes in environmental conditions. Also, our results predict a large increase in the area of suitable environment to the north of current populations. These areas could be regarded as eligible for the United Kingdom translocation plan. Similar outcomes were obtained for two butterfly species in Great Britain (Carroll et al., 2009), leading to similar predictions. However, we emphasise that extreme care should be taken before any decision is made to avoid any planned invasion (Webber et al., 2011). This should not be the case for the current translocation areas, since they are located within the current extent of occurrence of $D$. plantarius and they are close to an existing population, so they are at the interface between reintroduction and reinforcement (IUCN, 2012b). Hence, this translocation program appears as a suitable response for the conservation of this species, contrary to wide-range translocations from south to north that could appear as appealing in the light of our results. Such translocations would probably be bound to fail by neglecting the local adaptations of populations.

\subsection{Implications for the French strategy for the creation of protected areas}

D. plantarius is currently classified as "1-" in the French Strategy for Creation of Protected Areas (SCAP), which means that the species is not protected enough by the current network of protected areas, but lack of knowledge will preclude the creation of protected areas for this species (Coste et al., 2010). Initially, the SCAP ought to include species 
417 threatened by climate change, however, the effects of climate change have not yet been studied on any of the concerned species (Coste et al., 2010). Our results provide important updates for the SCAP by providing a first assessment of future effects of climate and land cover changes. Firstly, our findings confirm that climate and land cover changes will threaten D. plantarius. Secondly, we have quantified how environmental change will affect French populations of D. plantarius, and have identified a population very likely to resist environmental change. Therefore, the status of the species should be updated to "1+" (a vulnerable species but insufficiently protected). We suggest that monitoring should be carried out for the Lac d'Hourtin population and, if appropriate, protection measures should be applied by the SCAP.

\subsection{Uncertainty of predicted impacts of global changes}

The quality of our predictions is high due to the high performance of the calibrated models, which is an encouraging output for the first forecast of future environmental changes concerning the spider taxon. Such a high performance was expected here, and should be anticipated for other spider species, since spiders are believed to be strongly dependent on temperature and humidity (Entling et al., 2007). In spite of the high performance of our models, substantial variations occurred in predictions. Four main sources generated uncertainty in predictions: (1) initial datasets, (2) species distribution models, (3) general circulation models and (4) emission scenarios (Buisson et al., 2010). We addressed uncertainty due to the initial dataset by compiling an extensive database using the known records of D. plantarius throughout its range (see Appendix B); however the known distribution of this species may still remain insufficiently sampled (Duffey, 2012). Species distribution models are known to generate the largest variations in predictions (Buisson et al., 2010), which was observed here. The robustness of predictions was increased by the use of an appropriate ensemble forecasting procedure, since it provides the average trend of the best models, weighted by their performance (Araújo and New, 2007). Besides, when studying the suitability of locations for conservation programs, 
we included variability in the suitability cut-offs for ensemble models. Substantial variability also arose from global circulation models, which are known to be the second largest source of variability (Buisson et al., 2010). Again, we applied a consensus procedure to mitigate uncertainty. Lastly, substantial differences were observed between emission scenarios. Scenario A1B predicted a greater impact of global changes on $D$. plantarius than scenario B2A, but also predicted the appearance of larger areas of environmental suitability in the future. However, scenario A1B is more probable than scenario B2A, and our actual predictions might even have been underestimated, since it has been proven that the most extreme IPCC scenarios have underestimated the actual $\mathrm{CO}_{2}$ emissions since 2000 (Canadell et al., 2007; Raupach et al., 2007). In addition to these sources of uncertainty, we hypothesized that the ability of $D$. plantarius to disperse into newly-suitable areas and to track changes in environmental conditions is limited. Thus, we assume that the actual net change (i.e. the difference between current and future suitable ranges) will be worse than our predicted values, although this must be confirmed between the local distribution of spiders and microhabitat or microclimatic conditions (Marc et al., 1999; Prieto-Benítez and Méndez, 2011); such parameters cannot be included by a study of the dispersal abilities of $D$. plantarius. Uncertainties in the ability of $D$. plantarius to adapt to changing environmental conditions could also be partly answered by genetic analyses. A final point of uncertainty is related to the well-known relationship in models with the current state of knowledge. Hence, D. plantarius might be able to remain in areas predicted as unsuitable if microclimatic conditions prevail over macroclimate. In spite of all the inevitable uncertainties in our predictions, consensus emerges out of our predictions that there will be three significant effects of global changes on D. plantarius: (1) a decrease in environmental suitability within its suitable range, (2) a loss of suitable areas in the south of its current range, and (3) the appearance of newlysuitable areas to the north of its current range.

\subsection{Concluding remarks}


471 The methodology developed here proves that global change effects can and should be

472 included in conservation strategies for spiders, as well as for other invertebrate taxa.

473 Indeed, global change effects can be studied on the basis of limited data such as presence-

474 only data, and such studies are clearly lacking for invertebrate taxa (Bellard et al., 2012).

475 Since occurrence data is often the only data available for invertebrate taxa, the possibility

476 of studying future global change by means of species distribution models is clearly an

477 opportunity to seize for invertebrate conservation. Additionally, we aim at providing

478 sound information about the current status and the possible evolution of D. plantarius to

479 be taken in consideration for the next IUCN red list evaluation.

\section{Acknowledgements}

481 We sincerely thank Manon Vasseur, Arthur Colliot and Nicolas Dubos for their help in 482 collecting the data. We thank Piero Visconti for providing some land cover data. We are 483 grateful to Sara Goodacre, Eric Duffey and Morgane Barbet-Massin for perspicacious 484 discussions and to Céline Bellard for wise advice, discussion, and constructive criticism on 485 an earlier version of the manuscript. We thank W. Thuiller and D. Georges for their help, 486 as well as two anonymous reviewers. 


\section{References}

489

490

491

492

493

494

495

496

497

498

499

500

501

502

503

504

505

506

507

508

509

510

511

512

Alkemade, R., Oorschot, M., Miles, L., Nellemann, C., Bakkenes, M., Ten Brink, B., 2009. GLOBIO3: A Framework to Investigate Options for Reducing Global Terrestrial Biodiversity Loss. Ecosystems 12, 374-390.

Allouche, O., Tsoar, A., Kadmon, R., 2006. Assessing the accuracy of species distribution models: prevalence, kappa and the true skill statistic (TSS). J. Appl. Ecol. 43, 12231232.

Araújo, M.B., New, M., 2007. Ensemble forecasting of species distributions. Trends Ecol. Evol. 22, 42-7.

Araújo, M.B., Pearson, R.G., Thuiller, W., Erhard, M., 2005. Validation of species-climate impact models under climate change. Glob. Change Biol. 11, 1504-1513.

Barbet-Massin, M., Jiguet, F., Albert, C.H., Thuiller, W., 2012. Selecting pseudo-absences for species distribution models: how, where and how many? Method. Ecol. Evol. 3, 327-338.

Barbet-Massin, M., Thuiller, W., Jiguet, F., 2010. How much do we overestimate future local extinction rates when restricting the range of occurrence data in climate suitability models? Ecography 33, 878-886.

Barnosky, A.D., Hadly, E.A., Bascompte, J., Berlow, E.L., Brown, J.H., Fortelius, M., Getz, W.M., Harte, J., Hastings, A., Marquet, P.A., Martinez, N.D., Mooers, A., Roopnarine, P., Vermeij, G., Williams, J.W., Gillespie, R., Kitzes, J., Marshall, C., Matzke, N., Mindell, D.P., Revilla, E., Smith, A.B., 2012. Approaching a state shift in Earth's biosphere. Nature 486, 52-58.

Bellard, C., Bertelsmeier, C., Leadley, P., Thuiller, W., Courchamp, F., 2012. Impacts of climate change on the future of biodiversity. Ecol. Lett. 15, 365-377.

Bonnet, P., 1952. Disparition des Dolomèdes (Aranéides) du lac de Lourdes. Bull. de la Soc. d'Hist. Nat. de Toulouse 84, 151-153.

Breiman, L., 2001. Random Forests. Machine Learning 45, 5-32.

Breiman, L., Friedman, J.H., Olshen, R.A., Stone, C.J., 1984. Classification and Regression Trees, The Wadsworth statisticsprobability series. Chapman \& Hall, New York.

Buisson, L., Thuiller, W., Casajus, N., Lek, S., Grenouillet, G., 2010. Uncertainty in ensemble forecasting of species distribution. Global Change Biology 16, 1145-1157.

Canadell, J.G., Le Quéré, C., Raupach, M.R., Field, C.B., Buitenhuis, E.T., Ciais, P., Conway, T.J., Gillett, N.P., Houghton, R.A., Marland, G., 2007. Contributions to accelerating atmospheric $\mathrm{CO} 2$ growth from economic activity, carbon intensity, and efficiency of natural sinks. P. Natl. Acad. Sci. USA. 104, 18866-70.

Carroll, M.J., Anderson, B.J., Brereton, T.M., Knight, S.J., Kudrna, O., Thomas, C.D., 2009. Climate change and translocations: The potential to re-establish two regionally-extinct butterfly species in Britain. Biol. Conserv. 142, 2114-2121. 
Chapman, A.D., 2009. Numbers of Living Species in Australia and the World. Heritage 2, 84.

Clark, J.A., May, R.M., 2002. Taxonomic Bias in Conservation Research. Science 297, 191b-192.

Coste, S., Comolet-Tirman, J., Grech, G., Poncet, L., Siblet, J.-P., 2010. Stratégie National de Création d'Aires Protégées - Première phase d'étude - Volet Biodiversité. Service du Patrimoine Naturel, MNHN, Paris.

Dawson, T.P., Jackson, S.T., House, J.I., Prentice, I.C., Mace, G.M., 2011. Beyond predictions: biodiversity conservation in a changing climate. Science $332,53-8$.

Duffey, E., 1995. The distribution, status and habitats of Dolomedes fimbriatus (Clerck) and D. plantarius (Clerck) in Europe, in: Růžička, V. (Ed.), Proceedings of the 15th European Colloquium of Arachnology. Institute of Entomology, České Budějovice, pp. 54-65.

Duffey, E., 2012. Dolomedes plantarius (Clerck, 1757) (Araneae: Pisauridae): a reassessment of its ecology and distribution in Europe, with comments on its history at Redgrave and Lopham Fen, England. B. Brit. Arachnol. Soc. 15, 285-292.

Elith, J., Ferrier, S., Huettmann, F., Leathwick, J., 2005. The evaluation strip: A new and robust method for plotting predicted responses from species distribution models. Ecol. Model. 186, 280-289.

Entling, W., Schmidt, M.H., Bacher, S., Brandl, R., Nentwig, W., 2007. Niche properties of Central European spiders: shading, moisture and the evolution of the habitat niche. Global Ecol. Biogeogr. 16, 440-448.

Fielding, A.H., Bell, J.F., 1997. A review of methods for the assessment of prediction errors in conservation presence/absence models. Environ. Conserv. 24, 38-49.

Friedman, J.H., 1991. Multivariate adaptive regression splines. Ann. of Stat. 19, 1-141.

Gajdoš, P., Toft, S., Langemark, S., Scharff, N., 2000. The fishing spiders Dolomedes (Araneae, Pisauridae) in Denmark. Steenstrupia 25, 201-208.

Gorb, S.N., Barth, F.G., 1994. Locomotor Behavior during Prey-Capture of a Fishing Spider, Dolomedes plantarius (Araneae: Araneidae): Galloping and Stopping. J. Arachnol. 22, 89-93.

Greenstone, M.H., Clyde, M.E., Hultsch, A.-L., Farrow, R.A., Dowse, J.E., 1987. Ballooning Spiders in Missouri, USA, and New South Wales, Australia: Family and Mass Distributions. J. Arachnol. 15, 163-170.

Guisan, A., Thuiller, W., 2005. Predicting species distribution: offering more than simple habitat models. Ecol. Lett. 8, 993-1009.

Harms, D., Dunlop, J., Schütt, K., 2009. Neue Nachweise der gerandeten Wasserspinne Dolomedes plantarius in Brandenburg (Araneae, Pisauridae). Arachnol. Mitt. 37, 1-8.

Hastie, T., Tibshirani, R., 1990. Generalized Additive Models. Chapman and Hall, London. 
Hastie, T., Tibshirani, R., Buja, A., 1994. Flexible Discriminant Analysis by Optimal Scoring. J. Am. Stat. Assoc. 89, 1255-1270.

Hickling, R., Roy, D.B., Hill, J.K., Fox, R., Thomas, C.D., 2006. The distributions of a wide range of taxonomic groups are expanding polewards. Glob. Change Biol. 12, 450-455.

Hijmans, R.J., Cameron, S.E., Parra, J.L., Jones, P.G., Jarvis, A., 2005. Very high resolution interpolated climate surfaces for global land areas. Int. J. Climatol. 25, 1965-1978.

IPCC, 2007. IPCC Fourth Assessment Report: Climate Change 2007, Intergovernmental Panel on Climate Change. Intergovernmental Panel on Climate Change, Geneva.

IUCN, 2012a. IUCN Red List of Threatened Species. Version 2012.1.International Union for Conservation of Nature and Natural Resources, Cambridge.

IUCN, 2012b. IUCN Guidelines for Reintroductions and Other Conservation Translocations. IUCN Species Survival Commission.

Jiménez-Valverde, A., Decae, A.E., Arnedo, M.A., 2011. Environmental suitability of new reported localities of the funnelweb spider Macrothele calpeiana: an assessment using potential distribution modelling with presence-only techniques. J. Biogeogr. $38,1213-1223$.

Jiménez-Valverde, A., Lobo, J.M., 2007a. Potential distribution of the endangered spider Macrothele calpeiana (Araneae, Hexathelidae) and the impact of climate warming. Acta Zool. Sinica 53, 865-876.

Jiménez-Valverde, A., Lobo, J.M., 2007b. Threshold criteria for conversion of probability of species presence to either-or presence-absence. Acta Oecol. 31, 361-369.

Lehner, B., Döll, P., 2004. Development and validation of a global database of lakes, reservoirs and wetlands. J. Hydrol. 296, 1-22.

Liu, C., Berry, P.M., Dawson, T.P., Pearson, R.G., 2005. Selecting thresholds of occurrence in the prediction of species distributions. Ecography 28, 385-393.

Marc, P., Canard, A., Ysnel, F., 1999. Spiders (Araneae) useful for pest limitation and bioindication. Agr. Ecosyst. Environ. 74, 229-273.

McCullagh, P., Nelder, J.A., 1989. Generalized Linear Models, Second Edition, Generalized Linear Models Second Edition. Chapman and Hall.

PBL Netherlands Environmental Assessment Agency, 2012. Roads from Rio+20 Pathways to achieve global sustainability goals by 2050. PBL Netherlands Environmental Assessment Agency, The Hague.

Phillips, S.J., Anderson, R.P., Schapire, R.E., 2006. Maximum entropy modeling of species geographic distributions. Ecol. Model. 190, 231-259.

Prieto-Benítez, S., Méndez, M., 2011. Effects of land management on the abundance and richness of spiders (Araneae): A meta-analysis. Biol. Conserv. 144, 683-691. 
Ramirez-Villegas, J., Jarvis, A., 2010. Downscaling Global Circulation Model Outputs: The Delta Method Decision and Policy Analysis Working Paper No. 1. Centre for Tropical Agriculture, Colombia.

Raupach, M.R., Marland, G., Ciais, P., Le Quéré, C., Canadell, J.G., Klepper, G., Field, C.B., 2007. Global and regional drivers of accelerating $\mathrm{CO} 2$ emissions. P. Natl. Acad. Sci. USA. 104, 10288-93.

Ridgeway, G., 1999. The state of boosting. Comp. Sci. Stat. 31, 172-181.

Smith, H., 200o. The status and conservation of the fen raft spider (Dolomedes plantarius) at Redgrave and Lopham Fen National Nature Reserve, England. Biol. Conserv. 95, 153-164.

Smith, H., Baillie, S., 2011. The UK translocation programme for Dolomedes plantarius. http://www.dolomedes.org.uk/conservation/translocation.html (accessed 23/12/2012).

Stockman, A.K., Beamer, D.A., Bond, J.E., 2006. An evaluation of a GARP model as an approach to predicting the spatial distribution of non-vagile invertebrate species. Divers. Distrib. 12, 81-89.

Suter, R.B., 1999. Cheap Transport for Fishing Spiders (Araneae, Pisauridae): The Physics of Sailing on the Water Surface. J. Arachnol. 27, 489-496.

Thuiller, W., Lafourcade, B., Engler, R., Araújo, M.B., 2009. BIOMOD - a platform for ensemble forecasting of species distributions. Ecography 32, 369-373.

Vugdelić, M., 2006. Genetic relations within and among Dolomedes aquatic spiders. PhD thesis, University of East Anglia, Norwich.

Webber, B.L., Scott, J.K., Didham, R.K., 2011. Translocation or bust! A new acclimatization agenda for the 21st century? Trends Ecol. Evol. 26, 495-6; author reply $497-8$. 


\section{Authorship}

$628 \mathrm{BL}, \mathrm{MP}$ and FY designed the study. AC and MI contributed to design the

629 methodology. BL and MP collected data, with help from AC and MI. BL performed

630 modelling work. BL wrote the first draft of the manuscript, and all the authors

631 contributed substantially to writing.

632

633 
Table 1. Predicted average environmental suitability (ranging from 0 to 1000) of areas for Dolomedes plantarius within the prediction area. Areas are considered suitable if their suitability is above all of the predicted suitability cut-offs (above 352.0), of low suitability if their suitability is comprised between the maximum and minimum predicted suitability cut-offs (between 133.0 and 352.0) and unsuitable if their suitability is below all the predicted suitability cut-offs (below 133.0). The suitability cut-offs are calculated by maximizing the TSS at each pseudo-absence run. The average suitability of English populations is only based on natural populations. Sources of data are in Appendix S2.

A.

Prediction area

Suitable range

Existing populations

B.

English populations

Redgrave and Lopham Fen

South Wales

Pevensey levels

Translocation populations

C.

French populations

Brière

Marais de Lavour

Lacs de Conzieu

Lac d'Hourtin

Arles

Assérac (discovered in 2012)

\begin{tabular}{|c|c|c|c|c|c|c|}
\hline \multicolumn{7}{|c|}{ Environmental suitability } \\
\hline & \multicolumn{3}{|c|}{ A1B } & \multicolumn{3}{|c|}{$\mathrm{B} 2 \mathrm{~A}$} \\
\hline 2000 & 2020 & 2050 & 2080 & 2020 & 2050 & 2080 \\
\hline 96.7 & 97.5 & 104.0 & 112.0 & 102.7 & 97.9 & 105.8 \\
\hline 395.5 & 384.0 & 363.8 & 362.5 & 381.9 & 356.4 & 351.2 \\
\hline 601.3 & 530.4 & 455.5 & 396.1 & 535.6 & 479.5 & 451.8 \\
\hline 509.9 & 473.4 & 381.0 & 313.4 & 469.8 & 449.2 & 376.8 \\
\hline 454.0 & 398.2 & 327.0 & 273.8 & 413.8 & 355.4 & 302.8 \\
\hline 492.2 & 526.7 & 445.1 & 387.2 & 499.2 & 518.9 & 431.9 \\
\hline 581.2 & 493.8 & 370.3 & 279.3 & 495.1 & 471.4 & 394.2 \\
\hline 504.5 & 520.7 & 434.2 & 360.8 & 520.9 & 478.9 & 420.2 \\
\hline 412.8 & 285.8 & 184.2 & 145.0 & 289.0 & 235.3 & 215.1 \\
\hline 323.3 & 268.3 & 209.0 & 164.0 & 284.9 & 261.4 & 231.7 \\
\hline 231.2 & 110.0 & 59.2 & 48.2 & 117.4 & 79.4 & 67.8 \\
\hline 196.5 & 196.5 & 102.3 & 75.3 & 218.4 & 145.6 & 132.0 \\
\hline 650.6 & 506.7 & 378.0 & 289.8 & 536.7 & 467.9 & 425.2 \\
\hline 523.3 & 336.0 & 198.4 & 162.2 & 316.5 & 263.6 & 246.0 \\
\hline 171.9 & 156.9 & 106.4 & 76.2 & 165.1 & 149.5 & 123.1 \\
\hline
\end{tabular}

Suitability of environmental conditions by 2080

\begin{tabular}{cc}
\hline A1B & B2A \\
& \\
& \\
& \\
Low suitability & Low suitability \\
Suitable & Suitable \\
Low suitability & Suitable \\
Suitable & Suitable \\
& \\
Low suitability & Low suitability \\
Unsuitable & Unsuitable \\
Unsuitable & Unsuitable \\
Low suitability & Suitable \\
Low suitability & Low suitability \\
Unsuitable & Unsuitable
\end{tabular}




\section{Figure captions}

Fig. 1. Current and projected future environmental suitability of the Western Palaearctic for Dolomedes plantarius according to two different climate scenarios (A1B \& B2A). A. Current climate suitability; B. and C. environmental suitability for the 2020 according to A1B \& B2A scenarios respectively; D. and E. environmental suitability for the 2050 s according to A1B \& B2A respectively; F. and G. environmental suitability for the 2080 s according to A1B \& B2A respectively.

Fig. 2. Current and projected future binary maps of environmental suitability of the Western Palaearctic for Dolomedes plantarius according to two different climate scenarios (A1B \& B2A) using a threshold value for conversion. A. Current suitable areas; B. and C. suitable areas for the 2020 according to A1B \& B2A scenarios respectively; D. and E. suitable areas for the 2050 according to A1B \& B2A respectively; F. and G. suitable areas for the $2080 \mathrm{~s}$ according to $\mathrm{A} 1 \mathrm{~B} \& \mathrm{~B} 2 \mathrm{~A}$ respectively.

Figure 3. Changes in the predicted distribution range of $D$. plantarius by 2080 according to A. scenario A1B and B. scenario B2A. Unsuitable: areas that are currently unsuitable and will remain unsuitable in the future; Disappearing: area currently suitable that will lose their suitability in the future; Stable: area that are currently suitable and will still be suitable in the future; Appearing: areas that are currently not suitable but will become suitable in the future.

Figure 4. Predicted values of decrease (Lost), increase (New) and net change (NetChange; calculated as the sum of the decrease and increase in suitable areas) in suitable areas by ensemble forecasts according to the different global circulation models (GCM). For each GCM, the 10 pseudo-absence runs of ensemble forecasts are plotted. 
Figure 1
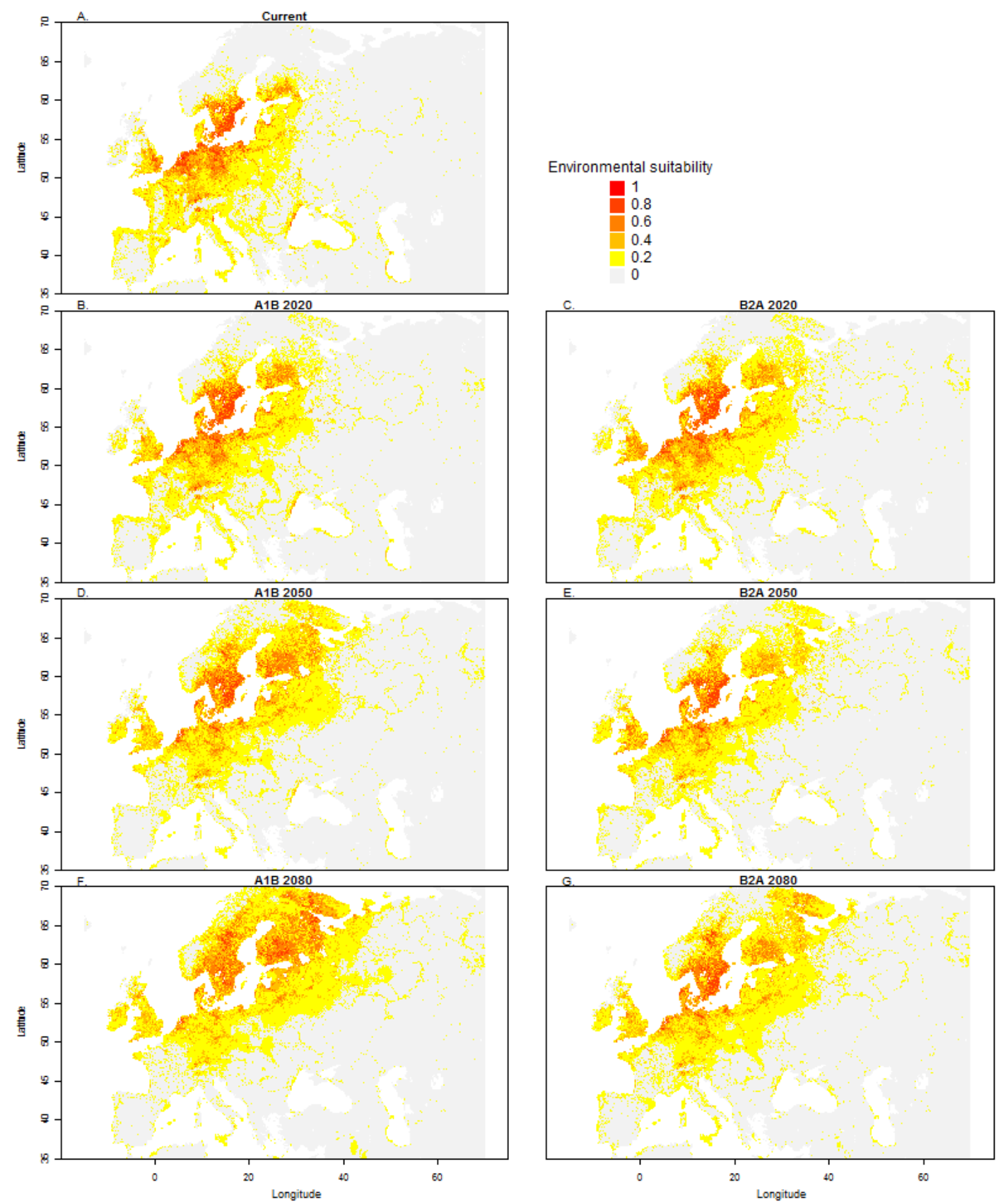
Figure 2

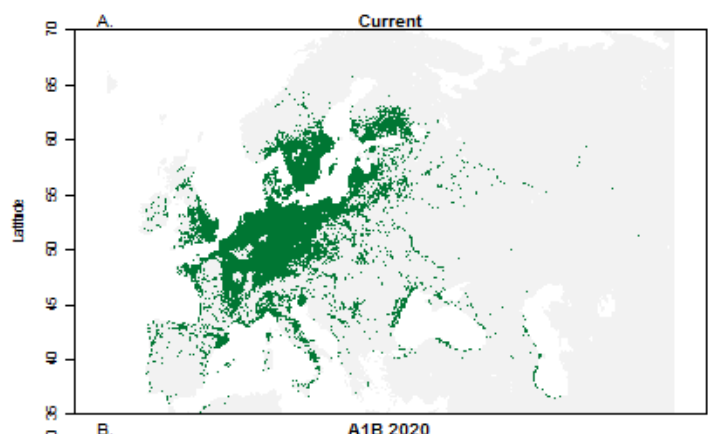

Environmental suitability

Suitable area
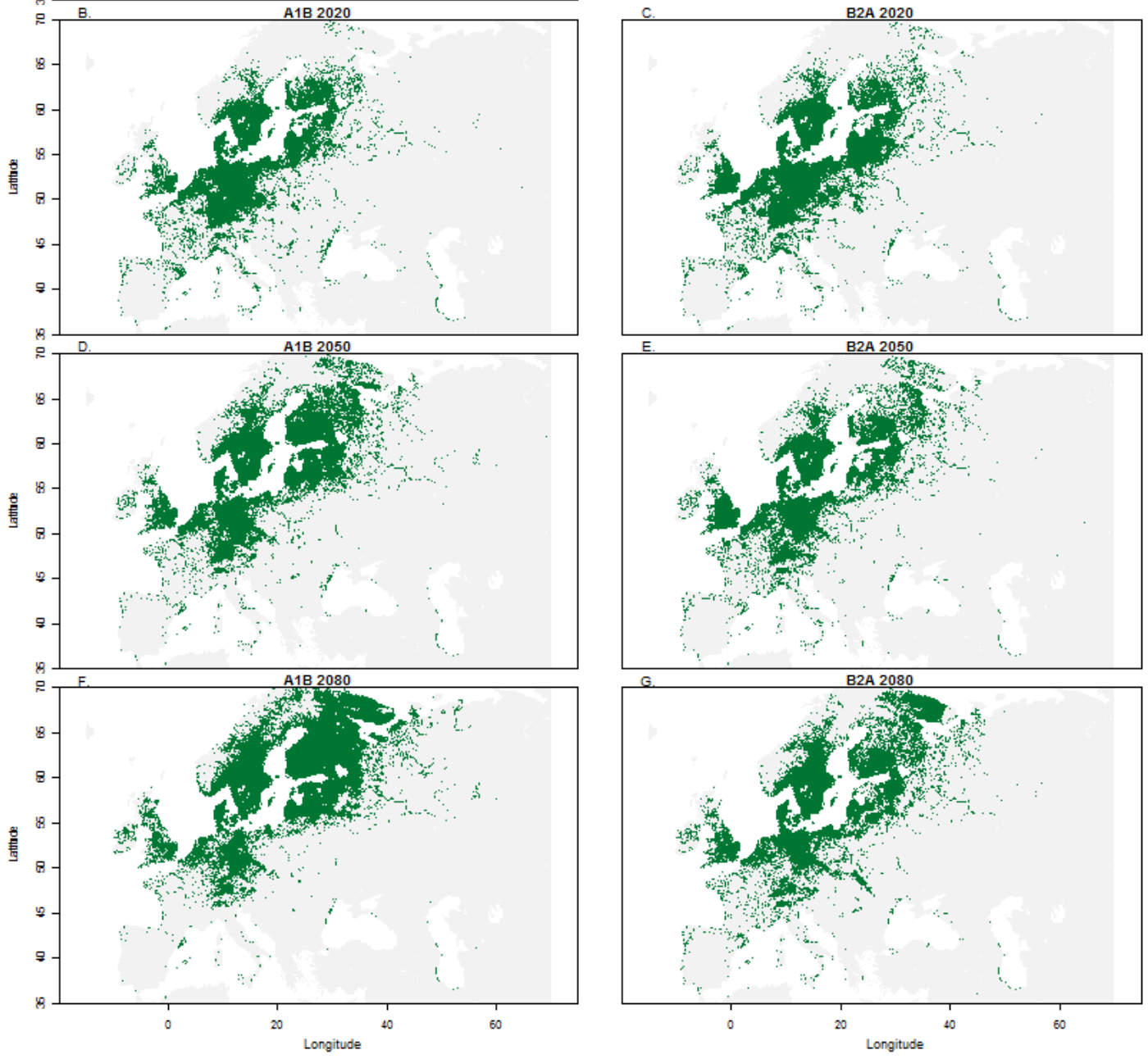
Figure 3
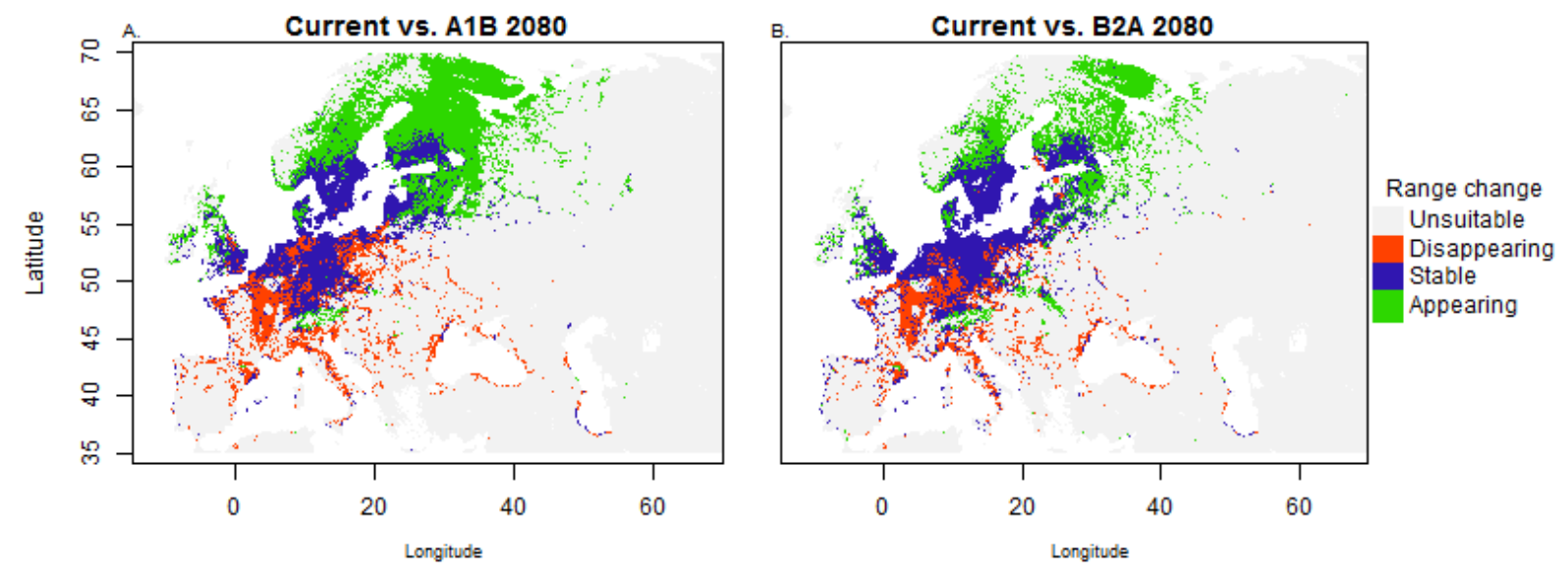
Figure 4

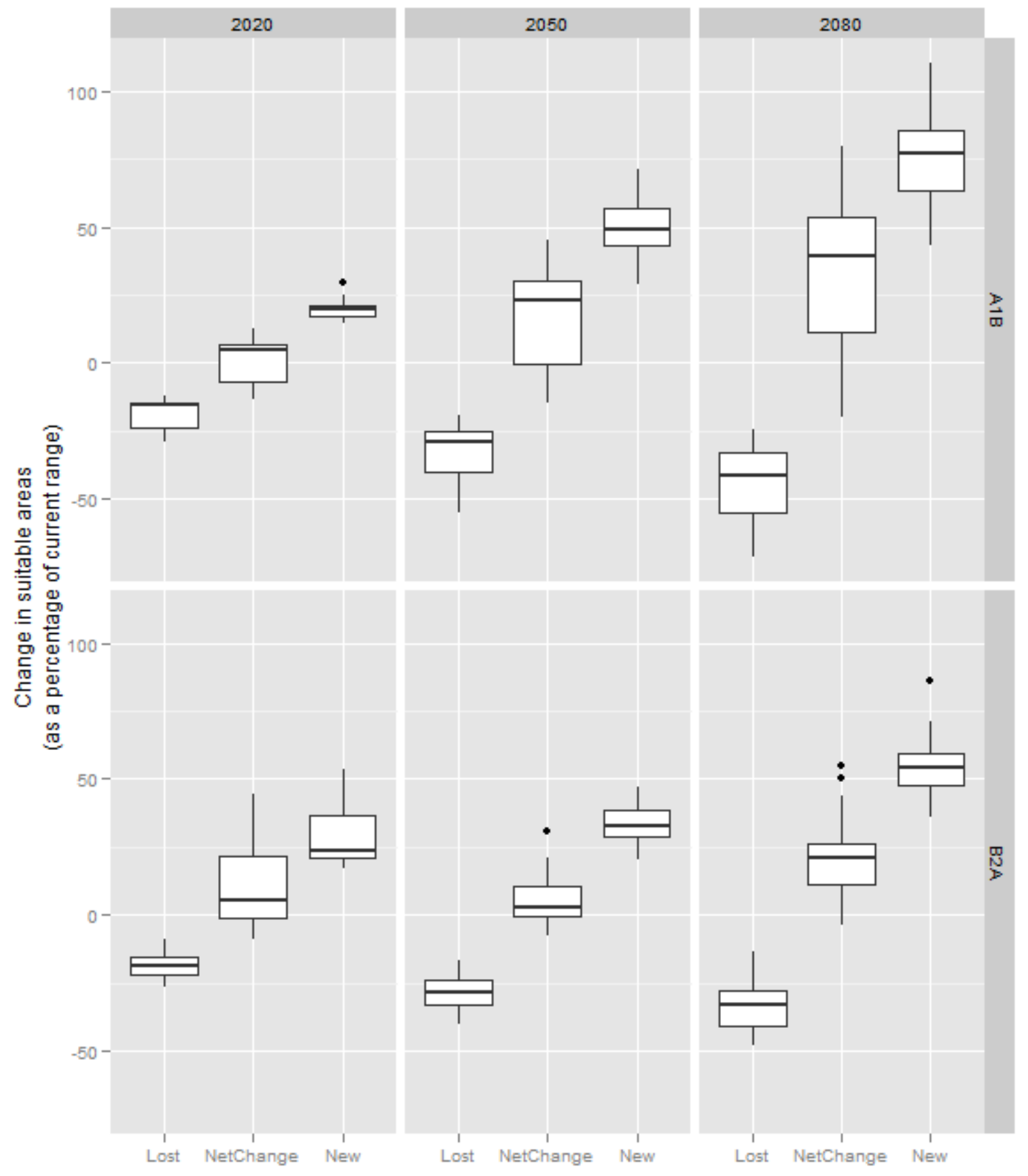




\section{Supporting Information}

Appendix A. Protocol of selection of variables for the models

Appendix B. Known records of Dolomedes plantarius

Appendix C. Sources of data

Appendix D. Locations of French and English populations of D. plantarius

Appendix E. Values of evaluation metrics

Appendix F. Response of D. plantarius to environmental predictor variables

Appendix G. Maps of range change by 2080 with known populations

Appendix H. Figures related to the uncertainty analysis 